\title{
A delayed frontorbital abscess caused by a penetrating nonmissile foreign body a bamboo stick
}

W en-ke Liu, Lu Ma, Bo-yong M ao

Department of Neurosurgery, West China Hospital, Sichuan University, Chengdu, Sichuan province, P.R. China

Address for correspondence:

Bo-yong Mao,

Department of Neurosurgery, West

China Hospital, Sichuan University,

Chengdu, Sichuan Province,

610 041, P.R. China.

E-mail: liuwenke781103@yahoo.

com.cn

DOI: $10.4103 / 0028-3886.51299$

\begin{abstract}
Abstrat
We report an interesting case of delayed frontal abscess caused by a penetrating nonmissile foreign body, a bamboo stick in a 1.5-year-old male child. A parietal craniotomy was performed, and the brain abscess was resected along with the foreign body without any damage to the surrounding brain tissue. He also received the appropriate antibiotics. The child made a good recovery.
\end{abstract}

Key words: Brain abscess, nonmissile foreign body, bamboo stick

\section{Introduction}

Brain abscess due to non-messile foreing body is relatively rare. We present a delayed frontorbital abscess caused by a penetrating nonmissile foreign body, a bamboo stick and discuss the characteristics.

\section{Case Report}

A 1.5-year-old child accidently fell from a height of 1.5 meters when his grand mother held the baby in her arms. Unfortunately, a bamboo stick penetrated into the left upper eyelid when the boy fell to the ground. His parents removed the superficial part of the stick exposed on the surface of the orbital skin and sent him to the local county clinic for a skin debridement. After almost one month, the child was brought to the Emergency Department with complaints of severe orbital swelling and slight headache.

On examination, his vital signs, vision, and papillary reaction were normal. There was a severe left frontal orbital swelling and proptosis. The muscle strength in the right limbs was graded at $4 / 5$. Computed tomography (CT) brain scan revealed a low density lesion in the left frontal lobe with perilesional edema [Figure 1a]. Coronal $\mathrm{CT}$, bone window, showed a breach in the left orbital roof in close proximity to the frontal lesion [Figure 1b].
Contrast magnetic resonance imaging (MRI) revealed a well formed abscess with thick capsule close to the foreign body, the bamboo stick. The bamboo stick was wrapped by granulation tissue throughout its length which enhanced with contrast [Figure 1c]. A parietal craniotomy was performed, and the brain abscess was totally resected along with the foreign body, the bamboo stick, without any damage to the surrounding brain tissue and blood vessels [Figure 1d]. The pus grew alpha $\mathrm{H}$ emolytic streptococcus sensitive to ceftriaxone. We also add metronidazole as an adjuvant therapy. The patient was continued on the antibiotics for three weeks. The child made a good recovery.

\section{Discussion}

Lately, there has been an increase in the number of cases of brain abscess secondary to neurosurgery and trauma. ${ }^{[1]}$ Injuries caused by objects with an impact velocity less than $100 \mathrm{~m} / \mathrm{sec}$ are known as nonmissile injuries. ${ }^{[2,3]}$ Penetrating nonmissile orbitocranial injuries caused by foreign body are uncommon civilian injuries which have some special features. Only a few reports are available in the international literature. ${ }^{[4]}$

Penetrating objects usually reach the frontal fossa through the upper eyelid and orbital roof. Children are more often injured through this mechanism because 

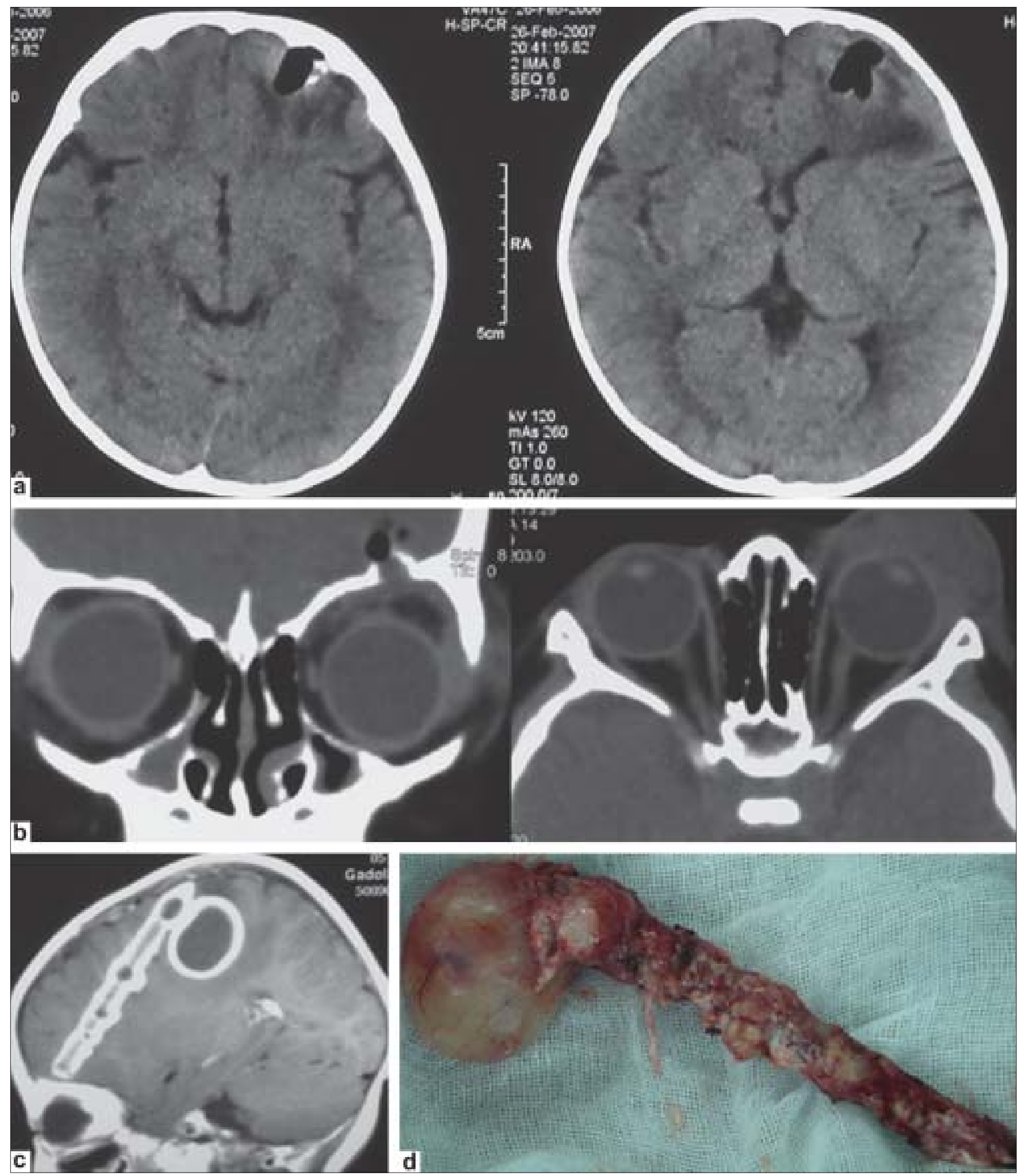

Figure 1: (a) Axial CT scans showing a low density lesion in the left frontal lobe surrounded by perifocal edema; (b) The coronal CT bone window image showing a breach in the orbital wall in close proximity to the low density image in the frontal lobe. This formed the entry point of the penetrating foreign body. Significant periorbital edema is seen on the axial image; (c) Enhanced MR image done after one month of injury showing a well-formed abscess with thick defined walls situated close to the foreign body. The latter is also surrounded by enhancing abscess capsule; (d) The bamboo stick surrounded by the granulation tissue of the abscess was completely resected 
their orbital bones are more fragile than that of adults. ${ }^{[5]}$ The orbital wounds often appear trivial with a tiny entry point [Figure 1b], which occasionally is not even visible. This fact together with a good Glasgow coma scale (GCS) makes it difficult to estimate the extent of the injury. In Chibbaro et al., series, ${ }^{[4]} 50 \%$ of such cases had GCS of 14 15 without any obvious evidence of intracranial injury. Central nervous system infection in these cases can be related to diverse factors, which include: Number of lobes involved, associated cerebrospinal fluid fistula, accessory sinuses involvement, and presence of retained foreign bodies. ${ }^{[6,7]}$ Cerebral abscesses develop after penetrating orbital and cranial wounds, especially if wooden foreign bodies are retained. In this patient, the type of trauma was nonmissile injury. He had insignificant symptoms and signs initially which made it difficult to make an appropriate diagnosis. Neuroimaging clearly demonstrated the route of injury, the retained foreign body and the complication, the abscess formation. Early plain X-ray and CT bone window would have demonstrated the presence of retained foreign body. MRI is a more useful modality of investigation to detect a wooden fragment than the plain X-ray and CT scan. ${ }^{[8,9]}$

Alpha H emolytic streptococcus was the pathogen grown in this patient and is the most common pathogen for brain abscess, whereas Staphylococcus is the commonest bacteria for brain abscess caused by penetrating cranial injury. ${ }^{[10]}$ Patients should be put on appropriate antibiotics based on the culture sensitivity. Neurosurgeons should have a high index of suspicion for orbital foreign bodies and possible intracranial injury in cases of penetrating orbital trauma. If an abscess is secondary to a retained foreign body, craniotomy is a better option. During the operation, if the wall of the abscess connected to the wooden foreign body is complete and thick, the most important factor is to protect the wall, to avoid the spread of pus.

In conclusion, we stress the importance of appropriate neuroimaging, CT bone window and contrast MRI in children with the nonmissile orbital injuries in children for early detection of the foreign body. Such cases should be treated aggressively by surgery as well as appropriate antibiotics to achieve good outcomes.

\section{References}

1. Carpenter J, Stapleton S, Holliman R. Retrospective analysis of 49 cases of brain abscess and review of the literature. Eur J Clin Microbiol Infect Dis 2007;26:1-11.

2. Clark WC, Muhlbauer MS, Watridge CB, Ray MW. Analysis of 76 civilian craniocerebral gunshot wounds. J Neurosurg 1986;65:9-14.

3. Rahman NU, Jamjoom A, Jamjoom ZA, Abu el-Asrar A. Orbito-cranial injury caused by penetrating metallic foreign bodies: Report of two cases. Int Ophthalmol 1997;21:13-7.

4. Chibbaro S, Tacconi L. Orbito-cranial injuries caused by penetrating non-missile foreign bodies. Experience with eighteen patients. Acta Neurochir (Wien) 2006;148:937-42.

5. Seider N, Gilboa M, Lautman E, Miller B. Delayed presentation of orbito-cerebral abscess caused by pencil-tip injury. Ophthal Plast Reconstr Surg 2006;22:316-7.

6. Shurbaji A, Rosahl SK, Feigl GC, Samii M. Metallic foreign body in the cavernous sinus causing delayed formation of brain abscess after missile injury. J Trauma 2006;60:1135-7.

7. Kaufman HH, Schwab K, Salazar AM. A national survey of neurosurgical care for penetrating head injury. Surg Neurol 1991;36:370-7.

8. Erdogan C, Hakyemez B, Yildirim N, Parlak M. Brain abscess and cystic brain tumor: Discrimination with dynamic susceptibility contrast perfusion-weighted MRI. J Comput Assist Tomogr 2005;29:663-7.

9. Glatt H.J, Custer PL, Barrett L, Sartor K. Magnetic resonance imaging and computed tomography in a model of wooden foreign bodies in the orbit. Ophthal Plast Reconstr Surg 1990;6:108-14.

10. Bank DE, Carolan PL. Cerebral abscess formation following ocular trauma: A hazard associated with common wooden toys. Pediatr Emerg Care 1993;9:285-8.

Accepted on 31-03-2009

Source of Support: Nil, Conflict of Interest: None declared. 